\title{
EDITORIAL
}

\section{Make the weird (worlds) great again!}

\author{
by Tomas Moe Skjølsvold
}

2016 has been a wild year for democracy. We have seen Donald Trump win the US presidential elections, while Brexit dominated the headlines half a year ago. Across Europe, including the Nordics, right- and left wing populist parties continue to gain foothold. Analysts now struggle to make sense of the situation and they will likely be occupied with both work and soul searching over the coming months and years.

The situation gives room for reflection also from an STS perspective. In our field, there is a strong tradition of giving voice to marginalized publics in the face of technocratic governance. There is also a strong tradition of encouraging public engagement with and participation in knowledge production and innovation, but also in governance more broadly.

Thus, it might instinctively be tempting to side with movements that so openly oppose what is interpreted as top-down, elitist control. One of the more interesting Brexit-slogans was "no more experts!" which could intuitively resonate well with scholars who sided with Brian Wynne's Cumbrian sheep farmers against overly confident scientific expertise in the 1990s. There is, however, no flood of STS-scholars standing up for the anti-scientific rhetoric of the Trump movement or the Brexit incident. Thankfully.

There are many good reasons for this. One of them is the totalizing character of the two movements many slogans. As an example, the idea of "making America great again" is a stellar exercise in reductionism, because it hides the thousands of particular sites where "America" is constantly produced, and the millions of modes of production that goes into making a monstrous hybrid such as the USA. The slogan conceals productive ideas about how to improve life in particular places and for particular actors, through the no-content notion of making "it" "great". It encompasses millions of particulars in a few "wholes", an approach that resonates poorly with the dedication of many STS-scholars to understand the complex peculiarities of the co-production of science, technology and society.

With this as a backdrop it is particularly troubling to observe that the social sciences at large seem to have failed in their analysis of the situation leading up to these incidents. It was unthinkable that Britain would leave the EU. It was considered a joke that mr. Trump could become the next president of the USA. Yet here we are, reflexively and collectively scratching our heads. How could we have missed the dynamics at play?

It would be worth exploring if any of the economic, institutional or cultural aspects of the current knowledge production regimes are partly responsible for producing such blind spots. Is there something in the ways we produce and think about knowledge, that pushes us away from research questions and projects which could better illuminate the situation? It would, for example, be interesting to explore the role different kinds of internationalization. As academics we are increasingly pushed in the direction of pursuing cross-country collaborations, often targeting issues deemed important by supra-national actors. The European Union and its many framework programs for research and innovation comes to mind. While these programs provide valuable funding and strong networks for research groups across Europe, they also format research activities and interests in ways that might not be fortunate for our collective understanding of the diversity of the continent.

Researcher mobility is another avenue worth exploring. Increasingly, scholars roam universities across continents for years, staying a year here, and a year there. While this boosts academic CV's and networks, and is imperative to what is currently labelled "excellence", it might have unintended side effects. It feeds into unfortunate gendered career patterns in academia. We might also ask critically if mobility as a response to top-down pressure concerning how an academic career should look helps in producing contemporary social analysis grounded in cultural understanding. If the global is small and local, as claimed by John Law, then we need to move from internationalization to "inter-localization" in order to ground ourselves and the kinds of knowledge we produce in the small, interconnected localities.

Another activity that is meaningful to many academics is publishing peer reviewed papers in top international journals. Yet, what is published in these journals often resonates best with the academic community itself. The academic "matters of concern" are making a piece of writing relevant to a global research community, or to funding bodies concerned with certain definitions of relevance and impact. Thus, the totalizing stories of the Brexit and Trump movements are not necessarily countered by rich accounts of diversity and specificity from scholarly voices, but just as often with other totalizing narratives about what it means to produce solid knowledge, what it means to be a good scientist, and how "science" and "society" relates to each other. Narratives about making nations "great" and making science "excellent" both narrow down, rather than open up for potential futures.

Thus, while "Science" seems to have lost interest in the local, specific, peculiar, strange and weird, it is probably from time- and space-specific places and issues that support for grand movements and narratives like "Trump" and "Brexit" emerges. This implies that 
in the years ahead, there is a need both to "zoom in" and to "zoom out", to study and understand collectives of different sizes, in order to avoid being shocked as we have been this year. It seems that we should work to re-award status to the weird or remarkable to complement the current focus on the generalizable and universal.

STS is particularly well equipped to take up this challenge, and the Nordic Journal of Science and technology studies will remain dedicated to the publication of scholarship that probes the many links between the local and global, the specific and the general, the empirical and theoretical. Recent events have shown that to understand the world, one must understand the weird, but also the relationships between different kinds of weirds and weirdworld links.

This issue includes four peer reviewed articles, that all focus on highly specific empirical topics, yet remain able to link these specificities to broader phenomena. Two papers deal with how experts relate to categories like "the public" in their output. Per Hetland studies the differences in the ways journalists and researchers popularize technological change. Researchers, he finds, tend to focus on the observable, which translates into relatively stable narratives. Journalists, on the other hand, create narratives anchored in future expectations, which means that they are more prone to write dramatic stories about change and turmoil.

Erik Thorstensen explores the language of the IPCC Working Group III's latest report, on mitigation of climate change, in order to try to understand if the IPCC attributes different meanings to concepts like "citizens", "stakeholders", "laypeople" and "the public".
The public, he finds, is largely treated as a barrier to progress, which need to be overcome if climate mitigation measures are to succeed. As such, the IPCC also produces a very narrow image of who people are, and what their roles are in climate mitigation.

Lene Pettersen looks at the use of social enterprise media in big organization, with a particular focus on how such software caters for the interpretation of space, and the logics of social interaction built into it. Pettersen illustrates how the logics of such platforms collide with, or work against the logics of similar tasks in the physical world, such as conversations and orientation in space.

Finally, Jenny Melind Bergschöld studies the use of a so-called vehicle-route problem solver (VRP) in the Norwegian home care service. This technology is meant to produce geographically optimal driving routes for care workers who drive from home to home. By applying the domestication perspective, Bergschöld shows how the technology "malfunctions", in the sense that it does not perform as expected, but also that it takes on different meanings in the everyday life of the care givers.

The Nordic Journal of Science and Technology Studies is likely to remain a space for the publication of diverse STS-scholarship also in 2017. Some will say that this makes the journal weird. Weird, however, does not mean irrelevant, it implies a different sort of relevance than the instrumental kind forced on scholars through slogans of excellence. Weird implies taking what goes on in the world seriously, looking closely, and allowing oneself to become surprised by what is actually happening. This is probably also our best bet if we want to be politically relevant in the years ahead. 